\title{
Role of berberine in Alzheimer's disease
}

This article was published in the following Dove Press journal:

Neuropsychiatric Disease and Treatment

3 October 2016

Number of times this article has been viewed

\author{
Zhiyou Cai',* \\ Chuanling Wang ${ }^{1, *}$ \\ Wenming Yang ${ }^{2}$ \\ 'Department of Neurology, Renmin \\ Hospital, Hubei University of \\ Medicine, Shiyan Renmin Hospital, \\ Shiyan, Hubei Province, ${ }^{2}$ Department \\ of Neurology, The First Affiliated \\ Hospital of Anhui University of \\ Chinese Medicine, Hefei, Anhui \\ Province, People's Republic of China \\ *These authors contributed equally \\ to this work
}

Correspondence: Zhiyou Cai

Department of Neurology, Renmin Hospital, Hubei University of Medicine, Shiyan Renmin Hospital, No 39 Chaoyang Middle Road, Shiyan 442000, Hubei

Province, People's Republic of China

$\mathrm{Tel} / \mathrm{fax}+867198637909$

Email caizy@hbmu.edu.cn

Wenming Yang

Department of Neurology, The First Affliated Hospital of Anhui University of Chinese Medicine, I 17, Meishan Road, Hefei, Anhui 23003I, People's Republic of China

Tel +8655I 62838707

Fax +86 55। 6282 I605

Email yangwm88I0@126.com
Abstract: Berberine, an important protoberberine isoquinoline alkaloid, has several pharmacological activities, including antimicrobial, glucose- and cholesterol-lowering, antitumoral, and immunomodulatory properties. Substantial studies suggest that berberine may be beneficial to Alzheimer's disease (AD) by limiting the pathogenesis of extracellular amyloid plaques and intracellular neurofibrillary tangles. Increasing evidence has indicated that berberine exerts a protective role in atherosclerosis related to lipid- and glucose-lowering properties, implicating that berberine has the potential to inhibit these risk factors for AD. This review also attempts to discuss the pharmacological basis through which berberine may retard oxidative stress and neuroinflammation to exhibit its protective role in AD. Accordingly, berberine might be considered a potential therapeutic approach to prevent or delay the process of AD. However, more detailed investigations along with a safety assessment of berberine are warranted to clarify the role of berberine in limiting these risk factors and AD-related pathologies.

Keywords: berberine, amyloid, tau, oxidative stress, neuroinflammation, risk factors

\section{Introduction}

Alzheimer's disease (AD) is an irreversible devastating neurodegenerative disorder, which affects the growing aging population. It has been confirmed that AD is the most common cause of dementia among older adults who are slowly deprived of memory and thinking skills and eventually the ability to carry out the simplest tasks and thereby suffer from physical or mental dysfunction, cognitive impairment, and dementia. Since the first “Alzheimer's disease" patient, Auguste D, was reported in November 1906 in the 37th Meeting of South-West German Psychiatrists in Tubingen by the clinical psychiatrist and neuroanatomist Alois Alzheimer, ${ }^{1-3} \mathrm{AD}$ has had a research history of more than 100 years. ${ }^{3,4}$ Various pathogeneses of AD have been put forward. It is well known that extracellular amyloid plaques and intracellular neurofibrillary tangles (NFTs) are the two classic pathological features of AD. ${ }^{5,6}$ Other recognized pathological features include synaptic degeneration, ${ }^{7}$ hippocampal neuronal loss, ${ }^{8}$ neuroinflammation, and oxidative stress. ${ }^{9-11}$

At present, several medications are used in research and clinical practice to intervene the progress of $\mathrm{AD}$, such as donepezil, rivastigmine, and galantamine and memantine. ${ }^{12-14}$ They may be beneficial to maintain thinking in good run, slow memory loss, and improve communication skills and help with certain behavioral problems. However, it seems that all these drugs gave the same results, with limited effects, even no effects, and more side effects. ${ }^{15} \mathrm{Up}$ to date, there are no medications that can prevent ${ }^{16}$ memory loss, cognitive impairment, and problems with learning, judgment, communication, and daily life. It is unlikely that none of the drugs can be successful for the cure of AD. ${ }^{14}$ 
Berberine, an important protoberberine alkaloid, is widely used in traditional Chinese medicine for hundreds of years. ${ }^{17}$ Several therapeutic effects of berberine have been identified against cancer, obesity, congestive heart failure, ${ }^{18}$ inflammation, atherosclerosis, neurodegenerative diseases, ${ }^{19}$ rheumatoid arthritis, cardiovascular diseases, ${ }^{17}$ and metabolic disorders, such as dyslipidemia, impaired fasting glucose, metabolic syndrome, and diabetes. ${ }^{18,20-22}$ Neuroprotective effects of berberine on stroke models have been evidenced by in vitro and in vivo research data. ${ }^{23,24}$ Recent research found that berberine improved behavioral functional impairment via enhancing cortical neurogenesis after brain ischemia induced by permanent middle cerebral artery occlusion. ${ }^{25}$ It has been found that berberine-mediated neuroprotection after ischemia is related to $\mathrm{Akt} / \mathrm{GSK} 3 \beta / \mathrm{ERK} 1 / 2$ survival/apoptotic signaling pathway as well as JNK and Caspase-3 activity inhibition. ${ }^{26,27}$ Studies along the years have demonstrated its beneficial effect on stroke ${ }^{28-30}$ and various neurodegenerative and neuropsychiatric disorders. ${ }^{19,26,31-34}$ Furthermore, berberine was identified as a second-generation anti-AD drug acting as an inhibitor of human acetylcholinesterase according to computational screening of synthetic molecules and dietary phytochemicals, resulting in reduced level of acetylcholine neurotransmitters. ${ }^{35}$ Hence, berberine will potentially be developed as a more effective therapeutic strategy for patients with AD. ${ }^{36,37}$

This review focuses on the role of berberine in AD. An overview is provided for the proposed general pathogenic mechanism of berberine in $\mathrm{AD}$ via regulating amyloid and tau pathology. Emphasis is also laid on the observation that berberine is beneficial to $\mathrm{AD}$ undergoing the limitation of neuroinflammation and oxidative stress. This review also discusses that berberine may restrict the role of risk factors involved in the pathogenesis of AD. Finally, a perspective is made that berberine is possibly an effective potential drug for the prevention and treatment of AD.

\section{Berberine}

Berberine (molecular formula, $\mathrm{C}_{20} \mathrm{H}_{19} \mathrm{NO}_{5}$ and molecular weight, $353.36 \mathrm{~g} / \mathrm{mol}$ ) is a bitter-tasting, yellow, plant alkaloid, with at least 3,000 years of medicinal use in Chinese and Ayurvedic medicine. Berberine has been identified in the roots, rhizomes, and stem bark of many plants, such as Hydrastis canadensis (goldenseal), Coptis chinensis (coptis or golden thread), Berberis aquifolium (Oregon grape), Berberis vulgaris (barberry), and Berberis aristata (tree turmeric). Historically, berberine has also been used as a yellow dye, due to its yellow color. In tradition, the main activity of berberine has been evidenced to possess antimicrobial properties against various bacteria, fungi, protozoans, helminths, chlamydia, and viruses. ${ }^{38-41}$ In addition to this antimicrobial property, berberine has been found to have numerous pharmacological effects. Preliminary research suggests that berberine may improve the quality of life and decreased the mortality rates in patients with chronic congestive heart failure. ${ }^{42,43}$ Based on human and animal scientific research, berberine has been suggested to aid in glycemic regulation and in favor of the prevention and treatment of diabetes. ${ }^{44-46}$ Berberine has also been evaluated as a treatment for hypercholesterolemia, via reducing serum triglycerides, cholesterol, and low-density lipoprotein (LDL) cholesterol. ${ }^{47-49}$ Multiple studies have indicated that berberine has been found to be beneficial to cancer, ${ }^{50}$ obesity, atherosclerosis, ${ }^{51}$ rheumatoid arthritis, cerebrovascular diseases, fever, headaches, high blood pressure, immune system, irritable bowel syndrome, leukemia, leukopenia, liver disease (alcoholic), osteoporosis, respiratory disorders, sedative, and so on. ${ }^{17}$ Berberine has been found to possess multiple neuroprotective effects and improve survival, development, and function of neurons, while protecting these electrically excitable brain cells. ${ }^{52}$ Furthermore, there has been strong evidence that berberine has a close relationship with neurodegenerative diseases, ${ }^{34}$ including AD, ${ }^{33}$ Parkinson's disease, ${ }^{53}$ and Huntington's disease. ${ }^{31}$

\section{Berberine and beta-amyloid pathology}

One classic pathological hallmark of $\mathrm{AD}$ is the accumulation of beta-amyloid $(A \beta)$ peptide derived from abnormal processing of amyloid precursor protein (APP). Various scientific research studies evidenced that the physiological generation of $A \beta$ from sequential APP proteolysis is the most critical and intriguing process in the development of AD. ${ }^{54,55}$ APP is a transmembrane protein expressed at high levels in the brain and many tissues, concentrated in the synapses of neurons, and metabolized in a rapid and highly complex fashion by a series of sequential proteases, including $\alpha$-secretase, $\beta$-secretase, and the intramembranous $\gamma$-secretase complex. Based on the physiological generation of $A \beta$ from sequential APP proteolysis, the process of APP includes two pathways: the amyloidogenic pathway and the nonamyloidogenic pathway. ${ }^{56,57}$ In the amyloidogenic pathway, cleavage of APP by $\beta$-secretase generates soluble peptide APP $\beta$ (sAPP $\beta$ ) and C-terminal fragment (C99). C99 can be cleaved by $\gamma$-secretase to yield the APP intracellular domain and A $\beta$. In the nonamyloidogenic pathway, $\alpha$-secretase cleaves APP, generating a soluble fragment of APP ( $\mathrm{APP} \alpha)$ and $\mathrm{C}$-terminal fragment, which is further cleaved by $\gamma$-secretase releasing the $\mathrm{p} 3$ peptide and APP intracellular domain. ${ }^{58-60}$ 


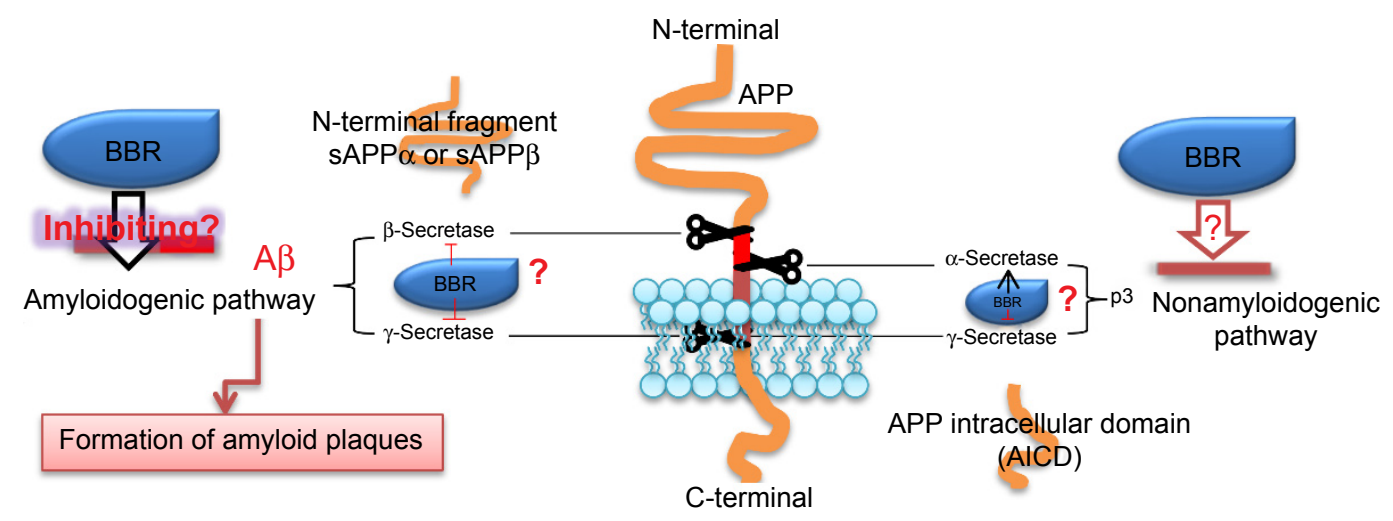

Figure I Possible mechanisms by which berberine modifies metabolism of APP.

Notes: In the amyloidogenic pathway, cleavage of APP by $\beta$-secretase generates soluble N-terminal fragment (sAPP $\beta$ ) and C-terminal fragment (C99). C99 can be cleaved by $\gamma$-secretase to yield the APP intracellular domain (AICD) and A $\beta$. In the nonamyloidogenic pathway, $\alpha$-secretase cleaves APP, generating a soluble fragment of APP (sAPP $\alpha$ ) and $C$-terminal fragment $(\alpha-C T F)$, which is further cleaved by $\gamma$-secretase releasing the 33 peptide and AICD. BBR could decrease $\beta$-secretase and $\gamma$-secretase and inhibit the process of amyloidogenic pathway, lowering the A $\beta$ release and the formation of amyloid plaques. The role of BBR in $\alpha$-secretase remains unclear in the nonamyloidogenic pathway. ? Represent that the mechanism is unclear.

Abbreviations: BBR, berberine; A $\beta$, beta-amyloid; AICD, APP intracellular domain; APP, amyloid precursor protein; sAPP, soluble APP.

Recent studies suggested that the neurobiological effects of berberine may contribute to clinical benefits for $\mathrm{AD}$ by decreasing the generation of $\mathrm{A} \beta^{61,62}$ (Figure 1). An in vitro study demonstrated that berberine inhibited $A \beta$-stimulated production of interleukin- 6 and monocyte chemotactic protein-1 and downregulated the expression of cyclo-oxygenase- 2 and induced nitric oxide synthase by blocking the phosphoinositide 3-kinase/protein kinase B and mitogen-activated protein kinase signaling pathways in primary microglial and BV2 cells. ${ }^{63}$ Durairajan et a ${ }^{64}$ demonstrated that berberine ameliorates $A \beta$ pathology, gliosis, and cognitive impairment in an $\mathrm{AD}$ transgenic mouse model. In a rabbit model of $\mathrm{AD}$, berberine treatment prevented the hippocampus from neurodegeneration, improved the behavior impairment, and lowered the activity of beta-site APP cleaving enzyme-1 (BACE-1). ${ }^{65}$ Asai et al ${ }^{66}$ found that berberine reduces $A \beta$ levels by modulating APP processing in human neuroglioma $\mathrm{H} 4$ cells (stably expressing Swedishtype of APP) at the range of berberine concentration without cellular toxicity. It was reported that berberine decreased $\mathrm{A} \beta$ levels via inhibiting the activity of BACE- $1,{ }^{67}$ which is a main $\beta$-secretase to determine the generation of $A \beta$. $\mathrm{Zhu}$ et $\mathrm{al}{ }^{68}$ reported that berberine decreases the production of $A \beta 40 / 42$ by inhibiting the expression of BACE via activation of the ERK1/2 pathway in HEK293 cells. Although the previous studies have reported that berberine can decrease the production of $A \beta$, the mechanism remains unclear. Berberine can pass through the blood-brain barrier and has multiple pharmacological properties in the brain, including neuroprotective and neurotrophic effects..$^{19,69,70}$ These data implicate that berberine would be a promising candidate for modifying APP metabolism via regulating APP processing or $\mathrm{A} \beta$ clearance.

\section{Berberine and tau pathology}

It is well accepted that NFTs are a characteristic neuropathological lesion of AD. They are composed of a highly phosphorylated form of the microtubule-associated protein tau. Hyperphosphorylation of tau disrupts its normal function in regulating axonal transport and leads to the formation of NFTs and toxic species of soluble tau. It was reported that berberine attenuated tau hyperphosphorylation and cytotoxicity induced by Calyculin A, which impaired the axonal transport in neuroblastoma-2a cells. ${ }^{71}$ Furthermore, it was found that berberine performed a significant reduction of Calyculin A-induced tau hyperphosphorylation at Ser198/199/202, Ser396, Ser404, Thr205, and Thr231, and it also recovered the $2 \mathrm{~A}$ activity of protein phosphates and limited glycogen synthase kinase- 3 beta (GSK-3 $\beta$ ) activation, as determined by phosphatase activity assay and GSK- $3 \beta$ phosphorylation at Tyr216 and Ser9 of tau. ${ }^{72}$ The exact mechanism how berberine restrained the hyperphosphorylation of tau is still in exploration. In consideration that degradation of hyperphosphorylated tau by the proteasome is inhibited by the actions of $A \beta$, berberine may decrease the hyperphosphorylation of tau by limiting the actions of $A \beta$.

\section{Berberine inhibits oxidative stress in AD}

It is a general acceptance that oxidative stress plays an essential role in $\mathrm{AD}$ pathogenesis via the multifunctional pathway. Increasing persuasive research demonstrated that 
berberine can limit the process of oxidative stress in the brain and central nervous system. Recent studies ${ }^{73}$ have evidenced that berberine can treat senile dementia by regulating neurotransmitter, antioxidative stress, and neuroinflammation and affecting metabolism and other multitarget pathways. Hence, the hypothesis has been made that berberine may ameliorate oxidative stress in $\mathrm{AD}$ and play a neuroprotective role in $\mathrm{AD}$ pathogenesis and that it is a potential avenue for AD treatment. ${ }^{73}$

\section{Oxidative stress in $A D$}

Oxidative stress has been proposed to be one of the most important factors in the pathogenesis of AD. Extensive oxidative research has been performed on the pathogenesis of AD over the past decade. A significant pathogenic feature is that oxidative stress may trigger an active, self-perpetuating cycle with chronic neuroinflammation while chronic neuroinflammation further promotes oxidative stress. Finally, this cycle may contribute to the occurrence of irreversible neuronal dysfunction and cell death in AD. Various studies have supported that oxidative stress is a culprit of cognitive impairment and dementia via destroying the connection of synapse in AD. There are abundant results indicating that the interaction between oxidative stress and neuroinflammation leads to $A \beta$ generation and the formation of NFTs. $A \beta$ production is a result of two sequential cleavages of the APP by two proteolytic enzymes, $\beta$-secretase and $\gamma$-secretase. Oxidative stress may upregulate $\beta$-secretase and $\gamma$-secretase and enhance $\mathrm{A} \beta$ production. Moreover, intracellular $\mathrm{A} \beta$ accumulation and the formation of NFTs contribute to a significant oxidative and inflammatory process that generates a vicious cycle between $\mathrm{A} \beta$ pathology and oxidation.

\section{Berberine inhibits oxidative stress}

A number of clinical and basic findings implicate that berberine is beneficial to a great variety of disorders via inhibiting the process of oxidative stress ${ }^{7-78}$ (Table 1). Berberine, the main active component of an ancient Chinese herb Coptis chinensis Franch., has been used to treat diabetes for thousands of years. ${ }^{79}$ Clinical and basic literature has implicated that berberine may serve as a new drug candidate in the treatment of diabetes on the basis of antioxidative stress by limiting the inflammatory parameters, antioxidative effect via down- and upregulation of GPx and $\mathrm{CuZn}$-superoxide dismutase expression, strong potential to improve the oxidant-antioxidant balance, and inhibiting the activation of RhoA/ROCK signaling. ${ }^{80-88}$ Moreover, berberine has such an activity as a therapeutic agent for lipid lowering, decreasing the level of serum cholesterol, triglycerides, and LDL cholesterol, which is associated with the inhibition of oxidation in mitochondria. ${ }^{79,89}$

\section{Berberine inhibits oxidative stress in $A D$}

It has been evidenced the therapeutic potential of berberine in different neurodegenerative diseases such as AD, Parkinson's disease, and Huntington's disease. ${ }^{90}$ Compelling research has demonstrated the beneficial role of berberine in neurodegenerative diseases, mainly due to its powerful antioxidant effect. ${ }^{33}$ Several results indicate that berberine plays a neuroprotective role against $A D$ via its antioxidative potential. ${ }^{73,91}$ The investigation conducted by Luo et $\mathrm{al}^{91}$ found the protective effects of berberine against $A \beta$-induced cell death in rat cortical neurons via decreasing the production of malondialdehyde and reactive oxygen species. Considering such an active, self-perpetuating cycle by which neuroinflammation interacts with oxidative stress, it is obvious that berberine may retard oxidative stress by limiting the neuroinflammation process in $\mathrm{AD}$ brain. In consideration that intracellular $A \beta$ accumulation and the formation of NFTs contribute to a significant oxidative and inflammatory process that generates a vicious cycle, berberine may suppress the $\mathrm{A} \beta$ and tau pathologies to lower the progress of oxidative stress. However, the exact role of berberine in the oxidative stress in AD remains unclear. The mechanism of berberine in the pathogenesis of AD involved in oxidative damage is not well clarified. Therefore, it is essential to further clarify the mechanism of berberine in the pathogenesis of AD involved in oxidative damage.

\section{Berberine retards neuroinflammation in AD?}

Several research studies have implicated that inflammation is involved in the pathogenesis of $\mathrm{AD}$, although it is still unclear exactly how inflammation plays a specific role in the course of the disease process. ${ }^{92,93}$ Since the late 1980s, the neuroinflammation hypothesis is supported by epidemiological retrospective observations and research from animal models, indicating that the chronic inflammation in $\mathrm{AD}$ enhances the disease process by various mechanisms ${ }^{93,94}$ Numerous observations have shown the concept that berberine may be protective against the development of $\mathrm{AD}$ via inhibiting the vicious process of neuroinflammation. ${ }^{19,63,95}$

\section{Neuroinflammation in AD}

A number of observations have evidenced the inflammatory processes in AD through multiple avenues. First, 
Table I Berberine inhibits oxidative stress in diseases

\begin{tabular}{|c|c|c|}
\hline Diseases & Possible antioxidative mechanism & References \\
\hline $\begin{array}{l}\text { Acute myocardial } \\
\text { injury }\end{array}$ & $\begin{array}{l}\text { Inhibiting the activity of LDH, CK, and MDA; declining the activity of SOD and CAT; } \\
\text { reducing COX-2 and iNOS expression in I/R myocardium; and increasing HO-I induction } \\
\text { in human aortic endothelial cells }\end{array}$ & 135 \\
\hline Aging & $\begin{array}{l}\text { Reduction of ROS production and oxidative DNA damage; suppressing the level of } \\
\text { constitutive mTOR- and DNA damage signaling; and reduction of the level of endogenous } \\
\text { oxidants and constitutive DNA damage }\end{array}$ & 136,137 \\
\hline Alzheimer's disease & $\begin{array}{l}\text { Reversing both the increase in malondialdehyde and the decrease in superoxide dismutase } \\
\text { activity induced by Calyculin A }\end{array}$ & $66,72,91$ \\
\hline Atherosclerosis & $\begin{array}{l}\text { Reducing oxidative stress and vascular inflammation and suppressing atherogenesis via a } \\
\text { mechanism that includes stimulation of AMPK-dependent UCP2 expression }\end{array}$ & 117 \\
\hline Cancer & Inhibiting reactive oxygen species generation and mitochondrial dysfunction & $138-140$ \\
\hline Cardiac failure & Downregulating phospholamban and exerting antioxidant activity & $|4|$ \\
\hline $\begin{array}{l}\text { Cerebral ischemia } \\
\text { diseases }\end{array}$ & $\begin{array}{l}\text { Attenuating ROS production and increasing cell viability, antioxidant defense (GSH and SOD), } \\
\text { and oxidant-sensitive proteins ( } \mathrm{HO}-\mathrm{I} \text { and } \mathrm{Nrf2} \text { ) }\end{array}$ & 77,125 \\
\hline Cognitive impairment & Mitigation of the oxidative stress burden & 142,109 \\
\hline Diabetes mellitus & $\begin{array}{l}\text { The influence on oxidative stress markers (malondialdehyde, urinary 8-hydroxy-2'- } \\
\text { deoxyguanosine, superoxide dismutase, aldose reductase, glutathione peroxidase, and total } \\
\text { antioxidant capacity) and limiting the inflammatory parameters (vascular adhesion molecule-I, } \\
\text { C-reactive protein and high-molecular-weight adiponectin); antioxidative effect via down- and } \\
\text { upregulation of GPx and CuZn-SOD expression, respectively; strong potential to improve } \\
\text { the oxidant-antioxidant balance; and inhibiting the activation of RhoA/ROCK signaling }\end{array}$ & $80-88,143-147$ \\
\hline Hepatic fibrosis & $\begin{array}{l}\text { Decreasing liver malondialdehyde concentration and increasing activities of liver superoxide } \\
\text { dismutase, catalase, and glutathione peroxidase }\end{array}$ & 148 \\
\hline Hepatic injury & $\begin{array}{l}\text { Reducing apoptosis, which is possibly involved with the modulation of the } \mathrm{PI} 3 \mathrm{~K} / \mathrm{Akt} / \mathrm{mTOR} \\
\text { signaling pathway, and modulating antioxidant status and inflammatory cytokines }\end{array}$ & $149-154$ \\
\hline Hypertension & $\begin{array}{l}\text { Limiting apoptosis and lowering expression of TLR4, Myd88, NF- } \mathrm{KB} \text {, IL-6, and TNF- } \alpha \text {; } \\
\text { inhibiting endoplasmic reticulum stress; and subsequently scavenging ROS leading to COX-2 } \\
\text { downregulation in carotid arteries }\end{array}$ & 155,156 \\
\hline $\begin{array}{l}\text { Ischemic acute renal } \\
\text { failure }\end{array}$ & $\begin{array}{l}\text { Via intonation on apoptosis and mitochondrial-dependent pathway in renal ischemia } \\
\text { reperfusion-induced mutilation }\end{array}$ & 157 \\
\hline Kidney damage & $\begin{array}{l}\text { The inhibition of oxidative/nitrosative stress, inflammation, autophagy, and apoptosis and the } \\
\text { suppression of NF-KB signaling pathway }\end{array}$ & $157-159$ \\
\hline Liver disease & $\begin{array}{l}\text { Inhibiting mitochondrial dysfunction, oxidative stress, and steatosis and activation of } \\
\text { AMP-activated protein kinase }\end{array}$ & $160-162$ \\
\hline Metabolic syndrome & $\begin{array}{l}\text { Inhibition of mitochondrial function, stimulation of glycolysis, activation of AMPK pathway, } \\
\text { suppression of adipogenesis, and induction of LDL receptor expression }\end{array}$ & 163 \\
\hline Parkinsonism & $\begin{array}{l}\text { Neuroprotection in 6-OHDA-induced PD by protecting dopaminergic neurons and reducing } \\
\text { the iron accumulation }\end{array}$ & 164 \\
\hline Retinal degeneration & Diminishing oxidative stress in the retina & 165 \\
\hline
\end{tabular}

Abbreviations: AMPK, adenosine 5'-monophosphate-activated protein kinase; ATF, cAMP-dependent transcription factor; CAT, catalase; CK, creatine phosphokinase; HO-I, heme oxygenase-I; IL, interleukin; LDL, low-density lipoprotein; LDH, lactate dehydrogenase; MCP-I, monocyte chemotactic protein I; MDA, malondialdehyde; MMP, matrix metalloproteinase; mTOR, mechanistic target of rapamycin; NF- $K B$, nuclear transcription factor kappa-light-chain-enhancer of activated B cells; Nrf2, nuclear factor erythroid 2 p45 related factor 2; ROS, reactive oxygen species; SOD, superoxide dismutase; TGF- $\beta$, transforming growth factor beta; TLR4, Toll-like receptor 4; TNF- $\alpha$, tumor necrosis factor-alpha; UCP2, uncoupling protein 2.

neuroinflammation contributes to $A \beta$ pathology since it enhances $A \beta$ generation and the failure of $A \beta$ clearance. ${ }^{94,96}$ Second, the supportive evidence has suggested that inflammation in $\mathrm{AD}$ induces the formation of NFTs, resulting from increase in the excessive abnormal phosphorylation of tau..$^{97,98}$ Third, clinical and basic data have demonstrated that cognitive decline and exaggerated behavior in $\mathrm{AD}$ may result in chronic neuroinflammation. ${ }^{99,100}$ Fourth, various studies have supported that a vicious cycle between neuroinflammation and oxidative stress is a significant pathogenic feature in $\mathrm{AD}$ where the cycle may magnify the $\mathrm{A} \beta$ pathology and the abnormal phosphorylation of tau. ${ }^{101,102}$ Fifth, the low-levellasting neuroinflammation in $\mathrm{AD}$ can be a marker of impaired adaptive immune responses leading to chronic inflammation, which induces the occurrence of AD-related following event, including the onset of cognitive impairment and dementia, the process of $A \beta$ pathology, and the abnormal phosphorylation of tau. ${ }^{100,103}$ 


\section{Berberine retards inflammation}

A growing body of evidence indicates that berberine retards inflammation, which is one of the pathological events in numerous disorders (Table 2). In addition to its own broad spectrum antimicrobial property, berberine has been reported to exert protective effects over various experimental models by inhibiting inflammation such as diabetes mellitus, obesity, heart diseases, cancers, cerebral ischemia, and hypertension (Table 2).

\section{Berberine alleviates neuroinflammation in $A D$ ?}

Extensive literature has pointed to the notion that berberine has the therapeutic potential in various neurodegenerative diseases by alleviating neuroinflammation. ${ }^{19,33,53,104}$ Convincing literature has demonstrated the beneficial role of berberine in
AD because of its anti-inflammatory properties. ${ }^{19,63}$ It has been believed that $A \beta$ accumulation and tau hyperphosphorylation are the motivating factors of neuroinflammation in brain on the basis of numerous investigations. ${ }^{93,105,106}$ Therefore, it is inferred that berberine suspends the process of $A \beta$ accumulation and tau hyperphosphorylation and then lowers the risk of neuroinflammation in AD brain. According to the vicious cycle that oxidative stress interacts with inflammation and each magnifies the pathological role in brain, ${ }^{98,99,107,108}$ it is believed that berberine suppresses the progression of oxidative stress and then achieves the effectiveness of bringing down neuroinflammation in AD. However, in the rat model of $\mathrm{AD}$, which was established by injecting $\mathrm{A} \beta$ into the rat's hippocampuses bilaterally, berberine chloride $(50 \mathrm{mg} / \mathrm{kg})$ by intragastric administration can ameliorate the spatial memory impairment and increase the expression of IL-1 $\beta$

Table 2 Berberine retards inflammation in different disorders

\begin{tabular}{|c|c|c|}
\hline Diseases & Possible anti-inflammation mechanism & References \\
\hline Allergic rhinitis & Reducing allergic inflammation significantly & 166 \\
\hline Alzheimer's disease & Reversing both the increase in MDA and the decrease in SOD activity induced by Calyculin A & $66,72,91$ \\
\hline Asthma & Inhibiting NF- $\kappa B$ signaling pathway & 167 \\
\hline Atherosclerosis & $\begin{array}{l}\text { Reducing oxidative stress and vascular inflammation and suppressing atherogenesis via a mechanism } \\
\text { that includes stimulation of AMPK-dependent UCP2 expression }\end{array}$ & 117,168 \\
\hline Cerebral ischemia diseases & $\begin{array}{l}\text { Attenuating ROS production and increasing cell viability, antioxidant defense (GSH and SOD), and } \\
\text { oxidant-sensitive proteins ( } \mathrm{HO}-\mathrm{I} \text { and } \mathrm{Nrf2} \text { ) }\end{array}$ & 77,125 \\
\hline Colon tumorigenesis & Through AMPK-dependent inhibition of mTOR activity and AMPK-independent inhibition of NF- $\mathrm{KB}$ & 169 \\
\hline Diabetes mellitus & Reducing oxidative stress & 20,87 \\
\hline Diabetic nephropathy & Inhibiting NF-KB-driven renal inflammation and TGF- $\beta / S$ mad3 signaling pathway & $170,17 \mid$ \\
\hline $\begin{array}{l}\text { Hepatic steatosis and } \\
\text { nonalcoholic steatohepatitis }\end{array}$ & Suppressing endoplasmic reticulum stress & 47,172 \\
\hline Hypertension & Limiting expression of TLR4, Myd88, NF-KB, IL-6, and TNF- $\alpha$ & 155,156 \\
\hline Irritable bowel syndrome & Reducing oxidative stress and inflammation response & 173 \\
\hline Kidney injury & Suppressing NF-KB signaling pathway & 159 \\
\hline Metabolic syndrome & $\begin{array}{l}\text { Inhibition of mitochondrial function, stimulation of glycolysis, activation of AMPK pathway, ATF-2 } \\
\text { phosphorylation, and MMP-2 expression; suppression of adipogenesis and induction of LDL } \\
\text { receptor expression }\end{array}$ & $20,163,174$ \\
\hline Mucus hypersecretion & $\begin{array}{l}\text { Decreased the release of inflammatory cytokines TNF- } \alpha, \text { IL-I } \beta, \text { MCP-I, and inflammatory cells in } \\
\text { bronchoalveolar lavage fluid }\end{array}$ & 175 \\
\hline $\begin{array}{l}\text { Myocardial ischemia/ } \\
\text { reperfusion injury }\end{array}$ & Reducing oxidative stress and inflammation response & 176,177 \\
\hline Obesity & Decreasing proinflammatory cytokines including TNF- $\alpha$ and IL-6 & 178 \\
\hline Osteoarthritis & Attenuating IL-I $\beta$ expression and inhibiting NF- $\kappa B$ signaling pathway & 179 \\
\hline Parkinson's disease & Reducing oxidative stress & 19 \\
\hline Reflux esophagitis & Improving SOD and HO-I levels & 180 \\
\hline Retinal diseases & Decreasing oxidative stress and the activation of microglia/macrophages & 165 \\
\hline Steatohepatitis & Against insulin resistance, inflammation, and lipid metabolism & 181 \\
\hline Traumatic brain injury & Limiting the production of inflammatory mediators by glial cells & 182 \\
\hline Ulcerative colitis & Inhibition of NF-KBp65 activation and increase in Nrf2 expression in colorectums & 183 \\
\hline
\end{tabular}

Abbreviations: AMPK, adenosine 5'-monophosphate-activated protein kinase; ATF, cAMP-dependent transcription factor; HO-I, heme oxygenase-I; IL, interleukin; LDL, low-density lipoprotein; LDH, lactate dehydrogenase; MCP-I, monocyte chemotactic protein I; MDA, malondialdehyde; MMP, matrix metalloproteinase; mTOR, mechanistic target of rapamycin; NF- $\mathrm{KB}$, nuclear transcription factor kappa-light-chain-enhancer of activated B cells; Nrf2, nuclear factor erythroid 2 p45-related factor 2; ROS, reactive oxygen species; SOD, superoxide dismutase; TGF- $\beta$, transforming growth factor beta; TLR4, Toll-like receptor 4; TNF- $\alpha$, tumor necrosis factor-alpha; UCP2, uncoupling protein 2 . 
and inducible nitric oxide synthase, and berberine might exaggerate the inflammation pathology. ${ }^{95}$ Overall, the role of berberine in the neuroinflammation in $\mathrm{AD}$ is controversial. Hence, it is necessary to reveal the exact role of berberine in the neuroinflammation of $\mathrm{AD}$ in the near future.

\section{Berberine decreases the role of risk factors in AD}

Various research studies prove that a host of risk factors beyond genetics have a close relation with the pathogenesis of AD. Numerous results indicate the relationship between cognitive decline and vascular risk factors such as age, heart disease, stroke, hyperhomocysteinemia, hypertension, diabetes, and obesity. Thus, decreasing the role of these risk factors may reduce the risk of cognitive decline and AD. ${ }^{109,110}$

It is well accepted that all these vascular risk factors contribute to the progress of atherosclerotic vascular diseases and the formation of atherosclerotic plaque, which is a common pathophysiology for cognitive decline, vascular dementia, and $\mathrm{AD}$. Increasing literature demonstrated that berberine will prevent the progress of atherosclerosis development. ${ }^{11,112}$ The antiatherosclerosis mechanism of berberine may be associated with regulating lipids, anti-inflammation and oxidative stress, reducing blood sugar, and inhibiting vascular smooth muscle cell proliferation via regulating the intracellular $\mathrm{Ca}^{2+}$ handling of smooth muscle cells. ${ }^{113-116}$ The model of atherosclerotic vulnerable plaque was formed by placing a collar around the carotid artery in ApoE-/- mice treated with homocysteine thiolactone. Berberine stabilizes atherosclerotic plaque in hyperhomocysteinemia ApoE-/- mice by activating peroxisome proliferator-activated receptor gamma and inhibiting oxidative stress in endothelial cells. ${ }^{51}$ Recruitment of monocytes to endothelial cells plays a crucial role during early stages of atherosclerosis development. Berberine was found to markedly reduce oxidized LDL-induced monocyte adhesion to human umbilical vein endothelial cells through antioxidative activation of AMPactivated protein kinase and inhibition of RhoA/Rho kinase pathway. ${ }^{117,118}$ Berberine also decreased adhesion molecule expression, including VCAM1 and ICAM1. The previous results implicated that berberine plays a protective role in the early stages of atherosclerosis. ${ }^{119}$ Berberine inhibits serum-induced cholesterol accumulation and vascular smooth muscle cell proliferation and migration, improves neointima formation, and plays a novel potentially atheroprotective role in macrophages. ${ }^{120-122}$ Clinical data showed that combination therapy with berberine and atorvastatin was more effective in preventing atherosclerotic processes than atorvastatin alone. ${ }^{123}$ A new insight into berberine's molecular mechanism and its therapeutic potential in the treatment of atherosclerosis was confirmed by showing that berberine inhibits inflammation by promoting autophagy through activation of the AMPK/mTOR signaling pathway. ${ }^{124}$

Basic research findings suggested that the combination of berberine with verapamil could enhance brain uptake of berberine and will provide a greater impact on neuroprotection in a rat model of transient global cerebral ischemia. ${ }^{125} \mathrm{It}$ was found that berberine dramatically lessened neurological deficits scores via increasing the activation of PI3K/Akt signaling and claudin-5 and decreasing NF- $\mathrm{KB}$ expression in ischemic brain. ${ }^{126,127}$ It is found that berberine can decrease triglycerides, improve metabolic syndrome, have a better glycemic control in diabetes, and act directly on the vasculature to promote vascular health via its ability to activate adenosine monophosphate-activated kinase. ${ }^{128}$ These compelling research data demonstrated that berberine may inhibit the pathogenesis of atherosclerosis and have the potential to reduce a host of risk factors for $\mathrm{AD}$, helping people stay healthy as they age.

\section{Conclusion and perspective}

Various research studies have demonstrated that berberine, an isoquinoline alkaloid of the protoberberine type found in an array of plants, plays a neuroprotective role in the different neurological disorders including cerebral ischemic disorders, ${ }^{26,129-131}$ multiple sclerosis, and various neurodegenerative and neuropsychiatric disorders ${ }^{19,25,109,132}$ besides reducing risk for various cancers, osteoporosis, osteoarthritis, nonalcoholic fatty liver disease, and other disorders. ${ }^{78,128}$ Compelling evidence has indicated that berberine may be beneficial to AD by limiting the pathogenesis of extracellular amyloid plaques and intracellular NFTs. In addition that berberine may inhibit the pathogenesis of atherosclerosis and have the potential to reduce a host of risk factors for $\mathrm{AD}$, berberine may also retard oxidative stress and neuroinflammation in the brain of AD. Accordingly, berberine may be a worthwhile drug to prevent or delay the process of AD.

There is substantial evidence from observational studies and clinical trials that conventional risk factors such as hypertension, diabetes, and dyslipidemia play a role in the development of AD. Targeting these risk factors will minimize the burden of $\mathrm{AD}$ in our aging population. Berberine can not only limit the role of these risk factors but also improve metabolic syndrome associated with $\mathrm{AD}$ as well. However, several studies have evaluated conflicting results 
that berberine enhances the development of atherosclerosis and foam cell formation by inducing scavenger receptor-A expression in macrophage ${ }^{133}$ and berberine-reduced apoptosis, HIF- $1 \alpha$, and p53 in cerebral tissue of middle cerebral artery occlusion rats. ${ }^{134}$ Therefore, the exact neuroprotective role of berberine remains indistinct. Despite that berberine may be a promising target to prevent and treat $\mathrm{AD}$ in the future on the basis of basic molecular biology research and clinical trials, further research is needed to clarify the role of berberine in limiting these risk factors and AD-related pathologies.

\section{Acknowledgments}

This work was supported by grants from the National Natural Science Foundation of China (No 81373599) to Wenming Yang and the Natural Science Foundation of Hubei Province (2015CFB260), the Hubei Province Health and Family Planning Scientific Research Project (WJ2015MB219), and the Shiyan Natural Science Foundation (15K70) and Renmin Hospital, Hubei University of Medicine to Doctor Zhiyou Cai.

\section{Disclosure}

The authors report no conflicts of interest in this work.

\section{References}

1. Gurwitz D. Auguste D and Alzheimer's disease. Lancet. 1997;350: 298.

2. Hippius H, Neundorfer G. The discovery of Alzheimer's disease. Dialogues Clin Neurosci. 2003;5(1):101-108.

3. Lage JM. 100 Years of Alzheimer's disease (1906-2006). J Alzheimers Dis. 2006;9(3 suppl):15-26.

4. Ramirez-Bermudez J. Alzheimer's disease: critical notes on the history of a medical concept. Arch Med Res. 2012;43(8):595-599.

5. Carreiras MC, Mendes E, Perry MJ, Francisco AP, Marco-Contelles J. The multifactorial nature of Alzheimer's disease for developing potential therapeutics. Curr Top Med Chem. 2013;13(15): 1745-1770.

6. Galimberti D, Scarpini E. Alzheimer's disease: from pathogenesis to disease-modifying approaches. CNS Neurol Disord Drug Targets. 2011; 10(2):163-174.

7. Riemer J, Kins S. Axonal transport and mitochondrial dysfunction in Alzheimer's disease. Neurodegener Dis. 2013;12(3):111-124.

8. Rampa A, Gobbi S, Belluti F, Bisi A. Emerging targets in neurodegeneration: new opportunities for Alzheimer's disease treatment? Curr Top Med Chem. 2013;13(15):1879-1904.

9. Luque-Contreras D, Carvajal K, Toral-Rios D, Franco-Bocanegra D, Campos-Pena V. Oxidative stress and metabolic syndrome: cause or consequence of Alzheimer's disease? Oxid Med Cell Longev. 2014; 2014:497802.

10. Dias C, Barbosa RM, Laranjinha J, Ledo A. Evaluation of mitochondrial function in the CNS of rodent models of Alzheimer's Disease - high resolution respirometry applied to acute hippocampal slices. Free Radic Biol Med. 2014;75(suppl 1):S37.

11. Galimberti D, Scarpini E. Inflammation and oxidative damage in Alzheimer's disease: friend or foe? Front Biosci (Schol Ed). 2011;3: 252-266.

12. Cacabelos R, Torrellas C, Carrera I, et al. Novel therapeutic strategies for dementia. CNS Neurol Disord Drug Targets. 2016;15:141-241.
13. Kumar A, Singh A, Ekavali. A review on Alzheimer's disease pathophysiology and its management: an update. Pharmacol Rep. 2015;67:195-203.

14. Ehret MJ, Chamberlin KW. Current practices in the treatment of Alzheimer disease: where is the evidence after the phase III trials? Clin Ther. 2015;37(8):1604-1616.

15. Mancuso C, Siciliano R, Barone E, Butterfield DA, Preziosi P. Pharmacologists and Alzheimer disease therapy: to boldly go where no scientist has gone before. Expert Opin Investig Drugs. 2011;20(9): 1243-1261.

16. Zemek F, Drtinova L, Nepovimova E, et al. Outcomes of Alzheimer's disease therapy with acetylcholinesterase inhibitors and memantine. Expert Opin Drug Saf. 2014;13(6):759-774.

17. Jin Y, Khadka DB, Cho WJ. Pharmacological effects of berberine and its derivatives: a patent update. Expert Opin Ther Pat. 2016;26(2):229-243.

18. Chang W, Li K, Guan F, et al. Berberine pretreatment confers cardioprotection against ischemia-reperfusion injury in a rat model of type 2 diabetes. J Cardiovasc Pharmacol Ther. Epub 2016 Feb 4.

19. Jiang W, Li S, Li X. Therapeutic potential of berberine against neurodegenerative diseases. Sci China Life Sci. 2015;58(6):564-569.

20. Caliceti C, Franco P, Spinozzi S, Roda A, Cicero AF. Berberine: new insights from pharmacological aspects to clinical evidences in the management of metabolic disorders. Curr Med Chem. 2016;23(14): 1460-1476.

21. Pirillo A, Catapano AL. Berberine, a plant alkaloid with lipid- and glucose-lowering properties: from in vitro evidence to clinical studies. Atherosclerosis. 2015;243:449-461.

22. Chang W, Zhang M, Meng Z, et al. Berberine treatment prevents cardiac dysfunction and remodeling through activation of $5^{\prime}$-adenosine monophosphate-activated protein kinase in type 2 diabetic rats and in palmitate-induced hypertrophic H9c2 cells. Eur J Pharmacol. 2015; 769:55-63.

23. Zhou XQ, Zeng XN, Kong H, Sun XL. Neuroprotective effects of berberine on stroke models in vitro and in vivo. Neurosci Lett. 2008; 447(7):31-36.

24. Yoo KY, Hwang IK, Kim JD, et al. Antiinflammatory effect of the ethanol extract of Berberis koreana in a gerbil model of cerebral ischemia/ reperfusion. Phytother Res. 2008;22(11):1527-1532.

25. Zou H, Long J, Zhang Q, et al. Induced cortical neurogenesis after focal cerebral ischemia - three active components from Huang-Lian-Jie-Du Decoction. J Ethnopharmacol. 2016;178:115-124.

26. Simoes Pires EN, Frozza RL, Hoppe JB, Menezes Bde M, Salbego $\mathrm{CG}$. Berberine was neuroprotective against an in vitro model of brain ischemia: survival and apoptosis pathways involved. Brain Res. 2014; 1557:26-33.

27. Benaissa F, Mohseni-Rad H, Rahimi-Moghaddam P, Mahmoudian M. Berberine reduces the hypoxic-ischemic insult in rat pup brain. Acta Physiol Hung. 2009;96(2):213-220.

28. Kim M, Shin MS, Lee JM, et al. Inhibitory effects of isoquinoline alkaloid berberine on ischemia-induced apoptosis via activation of phosphoinositide 3-kinase/protein kinase B signaling pathway. Int Neurourol J. 2014;18(3):115-125.

29. Li S, Wu C, Chen J, et al. An effective solution to discover synergistic drugs for anti-cerebral ischemia from traditional Chinese medicinal formulae. PLoS One. 2013;8(11):e78902.

30. Lin TY, Lin YW, Lu CW, Huang SK, Wang SJ. Berberine inhibits the release of glutamate in nerve terminals from rat cerebral cortex. PLoS One. 2013;8(6):e67215.

31. Jiang W, Wei W, Gaertig MA, Li S, Li XJ. Therapeutic effect of berberine on Huntington's disease transgenic mouse model. PLoS One. 2015;10(7):e0134142.

32. Friedemann T, Schumacher U, Tao Y, Leung AK, Schroder S. Neuroprotective activity of coptisine from Coptis chinensis (Franch). Evid Based Complement Alternat Med. 2015;2015:827308.

33. Ahmed T, Gilani AU, Abdollahi M, Daglia M, Nabavi SF, Nabavi SM. Berberine and neurodegeneration: a review of literature. Pharmacol Rep. 2015;67(5):970-979. 
34. Zhang J, Yang JQ, He BC, et al. Berberine and total base from rhizoma coptis chinensis attenuate brain injury in an aluminum-induced rat model of neurodegenerative disease. Saudi Med J. 2009;30(6):760-766.

35. Amat-Ur-Rasool H, Ahmed M. Designing second generation antialzheimer compounds as inhibitors of human acetylcholinesterase: computational screening of synthetic molecules and dietary phytochemicals. PLoS One. 2015;10(9):e0136509.

36. Mak S, Luk WW, Cui W, Hu S, Tsim KW, Han Y. Synergistic inhibition on acetylcholinesterase by the combination of berberine and palmatine originally isolated from Chinese medicinal herbs. $J$ Mol Neurosci. 2014;53(3):511-516.

37. Kim MH, Kim SH, Yang WM. Mechanisms of action of phytochemicals from medicinal herbs in the treatment of Alzheimer's disease. Planta Med. 2014;80(15):1249-1258.

38. Dziedzic A, Wojtyczka RD, Kubina R. Inhibition of oral streptococci growth induced by the complementary action of berberine chloride and antibacterial compounds. Molecules. 2015;20(8):13705-13724.

39. Wojtyczka RD, Dziedzic A, Kepa M, et al. Berberine enhances the antibacterial activity of selected antibiotics against coagulase-negative Staphylococcus strains in vitro. Molecules. 2014;19(5):6583-6596.

40. Harikumar KB, Kuttan G, Kuttan R. Inhibition of progression of erythroleukemia induced by Friend virus in BALB/c mice by natural products - berberine, curcumin and picroliv. J Exp Ther Oncol. 2008; 7(4):275-284.

41. Schmeller T, Latz-Bruning B, Wink M. Biochemical activities of berberine, palmatine and sanguinarine mediating chemical defence against microorganisms and herbivores. Phytochemistry. 1997;44(22): 257-266.

42. Zeng X, Zeng X. Relationship between the clinical effects of berberine on severe congestive heart failure and its concentration in plasma studied by HPLC. Biomed Chromatogr. 1999;13(7):442-444.

43. Chen K, Li G, Geng F, et al. Berberine reduces ischemia/reperfusioninduced myocardial apoptosis via activating AMPK and PI3K-Akt signaling in diabetic rats. Apoptosis. 2014;19(6):946-957.

44. Di Pierro F, Villanova N, Agostini F, Marzocchi R, Soverini V, Marchesini G. Pilot study on the additive effects of berberine and oral type 2 diabetes agents for patients with suboptimal glycemic control. Diabetes Metab Syndr Obes. 2012;5:213-217.

45. Xie X, Meng X, Zhou X, Shu X, Kong H. [Research on therapeutic effect and hemorrheology change of berberine in new diagnosed patients with type 2 diabetes combining nonalcoholic fatty liver disease]. Zhongguo Zhong Yao Za Zhi. 2011;36:3032-3035.

46. Zhang Y, Li X, Zou D, et al. Treatment of type 2 diabetes and dyslipidemia with the natural plant alkaloid berberine. J Clin Endocrinol Metab. 2008;93(7):2559-2565.

47. Ghareeb DA, Khalil S, Hafez HS, et al. Berberine reduces neurotoxicity related to nonalcoholic steatohepatitis in rats. Evid Based Complement Alternat Med. 2015;2015:361847.

48. Dong H, Zhao Y, Zhao L, Lu F. The effects of berberine on blood lipids: a systemic review and meta-analysis of randomized controlled trials. Planta Med. 2013;79(6):437-446.

49. Meng S, Wang LS, Huang ZQ, et al. Berberine ameliorates inflammation in patients with acute coronary syndrome following percutaneous coronary intervention. Clin Exp Pharmacol Physiol. 2012;39(5):406-411.

50. Naveen CR, Gaikwad S, Agrawal-Rajput R. Berberine induces neuronal differentiation through inhibition of cancer stemness and epithelialmesenchymal transition in neuroblastoma cells. Phytomedicine. 2016; 23(7):736-744.

51. Li H, He C, Wang J, et al. Berberine activates peroxisome proliferatoractivated receptor gamma to increase atherosclerotic plaque stability in Apoe mice with hyperhomocysteinemia. J Diabetes Investig. Epub 2016 Mar 7.

52. Kysenius K, Huttunen HJ. Stress-induced upregulation of VLDL receptor alters Wnt-signaling in neurons. Exp Cell Res. 2016;340(2) 238-247.

53. Kim M, Cho KH, Shin MS, et al. Berberine prevents nigrostriatal dopaminergic neuronal loss and suppresses hippocampal apoptosis in mice with Parkinson's disease. Int J Mol Med. 2014;33(4):870-878.
54. Selivanova A, Winblad B, Dantuma NP, Farmery MR. Biogenesis and processing of the amyloid precursor protein in the early secretory pathway. Biochem Biophys Res Commun. 2007;357(4):1034-1039.

55. Beel AJ, Sakakura M, Barrett PJ, Sanders CR. Direct binding of cholesterol to the amyloid precursor protein: an important interaction in lipid-Alzheimer's disease relationships? Biochim Biophys Acta. 2010; 1801(8):975-982.

56. Deng Y, Wang Z, Wang R, et al. Amyloid-beta protein (Abeta) Glu11 is the major beta-secretase site of beta-site amyloid-beta precursor protein-cleaving enzyme 1 (BACE1), and shifting the cleavage site to Abeta Asp1 contributes to Alzheimer pathogenesis. Eur J Neurosci. 2013;37:1962-1969.

57. Torres M, Jimenez S, Sanchez-Varo R, et al. Defective lysosomal proteolysis and axonal transport are early pathogenic events that worsen with age leading to increased APP metabolism and synaptic Abeta in transgenic APP/PS1 hippocampus. Mol Neurodegener. 2012; 7:59.

58. Shimojo M, Sahara N, Mizoroki T, et al. Enzymatic characteristics of I213T mutant presenilin-1/gamma-secretase in cell models and knock-in mouse brains: familial Alzheimer disease-linked mutation impairs gamma-site cleavage of amyloid precursor protein C-terminal fragment beta. J Biol Chem. 2008;283(24):16488-16496.

59. McPhie DL, Lee RK, Eckman CB, et al. Neuronal expression of beta-amyloid precursor protein Alzheimer mutations causes intracellular accumulation of a C-terminal fragment containing both the amyloid beta and cytoplasmic domains. J Biol Chem. 1997;272(40): 24743-24746.

60. Shoji M, Kawarabayashi T, Sato M, et al. Systemic overexpression of a C-terminal fragment of human amyloid beta-protein precursor causes accumulation of Alzheimer beta-amyloid fibrils in pancreas of transgenic mice. Gerontology. 1996;42(suppl 1):48-56.

61. Ji HF, Shen L. Berberine: a potential multipotent natural product to combat Alzheimer's disease. Molecules. 2011;16(8):6732-6740.

62. Haghani M, Shabani M, Tondar M. The therapeutic potential of berberine against the altered intrinsic properties of the CA1 neurons induced by Abeta neurotoxicity. Eur J Pharmacol. 2015; 758:82-88.

63. Jia L, Liu J, Song Z, et al. Berberine suppresses amyloid-beta-induced inflammatory response in microglia by inhibiting nuclear factor-kappaB and mitogen-activated protein kinase signalling pathways. J Pharm Pharmacol. 2012;64(10):1510-1521.

64. Durairajan SS, Liu LF, Lu JH, et al. Berberine ameliorates beta-amyloid pathology, gliosis, and cognitive impairment in an Alzheimer's disease transgenic mouse model. Neurobiol Aging. 2012;33: 2903-2919.

65. Panahi N, Mahmoudian M, Mortazavi P, Hashjin GS. Effects of berberine on beta-secretase activity in a rabbit model of Alzheimer's disease. Arch Med Sci. 2013;9:146-150.

66. Asai M, Iwata N, Yoshikawa A, et al. Berberine alters the processing of Alzheimer's amyloid precursor protein to decrease Abeta secretion. Biochem Biophys Res Commun. 2007;352(2):498-502.

67. Jung HA, Min BS, Yokozawa T, Lee JH, Kim YS, Choi JS. AntiAlzheimer and antioxidant activities of coptidis rhizoma alkaloids. Biol Pharm Bull. 2009;32(8):1433-1438.

68. Zhu F, Wu F, Ma Y, et al. Decrease in the production of beta-amyloid by berberine inhibition of the expression of beta-secretase in HEK293 cells. BMC Neurosci. 2011;12:125.

69. Lu J, Cao Y, Cheng K, et al. Berberine regulates neurite outgrowth through AMPK-dependent pathways by lowering energy status. Exp Cell Res. 2015;334(2):194-206.

70. Ma X, Jiang Y, Wu A, et al. Berberine attenuates experimental autoimmune encephalomyelitis in C57 BL/6 mice. PLoS One. 2010;5(10): e13489.

71. Liu X, Zhou J, Abid MD, et al. Berberine attenuates axonal transport impairment and axonopathy induced by Calyculin A in N2a cells. PLoS One. 2014;9(4):e93974.

72. Yu G, Li Y, Tian Q, et al. Berberine attenuates calyculin A-induced cytotoxicity and Tau hyperphosphorylation in HEK293 cells. J Alzheimers Dis. 2011;24(3):525-535. 
73. Huang M, Chen S, Liang Y, Guo Y. The role of berberine in the multitarget treatment of senile dementia. Curr Top Med Chem. 2016;16(8): 867-873.

74. Tan Y, Tang Q, Hu BR, Xiang JZ. Antioxidant properties of berberine on cultured rabbit corpus cavernosum smooth muscle cells injured by hydrogen peroxide. Acta Pharmacol Sin. 2007;28(12):1914-1918.

75. Xiao X, Liu J, Hu J, et al. Protective effects of protopine on hydrogen peroxide-induced oxidative injury of $\mathrm{PC} 12$ cells via $\mathrm{Ca}(2+)$ antagonism and antioxidant mechanisms. Eur J Pharmacol. 2008;591(1-3):21-27.

76. Luo T, Zhang H, Zhang WW, et al. Neuroprotective effect of jatrorrhizine on hydrogen peroxide-induced cell injury and its potential mechanisms in PC12 cells. Neurosci Lett. 2011;498(3):227-231.

77. Hsu YY, Chen CS, Wu SN, Jong YJ, Lo YC. Berberine activates Nrf2 nuclear translocation and protects against oxidative damage via a phosphatidylinositol 3-kinase/Akt-dependent mechanism in NSC34 motor neuron-like cells. Eur J Pharm Sci. 2012;46(5):415-425.

78. Abd El-Wahab AE, Ghareeb DA, Sarhan EE, Abu-Serie MM, El Demellawy MA. In vitro biological assessment of Berberis vulgaris and its active constituent, berberine: antioxidants, anti-acetylcholinesterase, anti-diabetic and anticancer effects. BMC Complement Altern Med. 2013;13:218.

79. Yin J, Xing H, Ye J. Efficacy of berberine in patients with type 2 diabetes mellitus. Metabolism. 2008;57(5):712-717.

80. Dai P, Wang J, Lin L, Zhang Y, Wang Z. Renoprotective effects of berberine as adjuvant therapy for hypertensive patients with type 2 diabetes mellitus: evaluation via biochemical markers and color Doppler ultrasonography. Exp Ther Med. 2015;10(3):869-876.

81. Rios JL, Francini F, Schinella GR. Natural products for the treatment of type 2 diabetes mellitus. Planta Med. 2015;81(12-13):975-994.

82. Zhou J, Zhou S, Tang J, et al. Protective effect of berberine on beta cells in streptozotocin- and high-carbohydrate/high-fat diet-induced diabetic rats. Eur J Pharmacol. 2009;606(1-3):262-268.

83. Rahigude AB, Kaulaskar SV, Bhutada PS. Possible therapeutic potential of berberine in diabetic osteopathy. Med Hypotheses. 2012;79(4): 440-444.

84. Chatuphonprasert W, Lao-Ong T, Jarukamjorn K. Improvement of superoxide dismutase and catalase in streptozotocin-nicotinamideinduced type 2-diabetes in mice by berberine and glibenclamide. Pharm Biol. Epub 2013 Nov 5.

85. Xie X, Chang X, Chen L, et al. Berberine ameliorates experimental diabetes-induced renal inflammation and fibronectin by inhibiting the activation of RhoA/ROCK signaling. Mol Cell Endocrinol. 2013; 381(1-2):56-65

86. Deng XW, Xie N. [Progress of berberine for treatment of type 2 diabetes]. Zhongguo Zhong Yao Za Zhi. 2014;39:1374-1378.

87. Li Z, Geng YN, Jiang JD, Kong WJ. Antioxidant and anti-inflammatory activities of berberine in the treatment of diabetes mellitus. Evid Based Complement Alternat Med. 2014;2014:289264.

88. Liu L, Liu J, Gao Y, Yu X, Xu G, Huang Y. Uncoupling protein-2 mediates the protective action of berberine against oxidative stress in rat insulinoma INS-1E cells and in diabetic mouse islets. Br J Pharmacol. 2014;171(13):3246-3254

89. Yin J, Gao Z, Liu D, Liu Z, Ye J. Berberine improves glucose metabolism through induction of glycolysis. Am J Physiol Endocrinol Metab. 2008;294(1):E148-E156.

90. Kumar A, Ekavali, Chopra K, Mukherjee M, Pottabathini R, Dhull DK. Current knowledge and pharmacological profile of berberine: an update. Eur J Pharmacol. 2015;761:288-297.

91. Luo T, Jiang W, Kong Y, et al. The protective effects of jatrorrhizine on beta-amyloid (25-35)-induced neurotoxicity in rat cortical neurons. CNS Neurol Disord Drug Targets. 2012;11:1030-1037.

92. Kizilarslanoglu MC, Kara O, Yesil Y, et al. Alzheimer disease, inflammation, and novel inflammatory marker: resistin. Turk J Med Sci. 2015;45(5):1040-1046.

93. De Felice FG, Ferreira ST. Inflammation, defective insulin signaling, and mitochondrial dysfunction as common molecular denominators connecting type 2 diabetes to Alzheimer disease. Diabetes. 2014;63(7):2262-2272.
94. Wyss-Coray T, Rogers J. Inflammation in Alzheimer disease-a brief review of the basic science and clinical literature. Cold Spring Harb Perspect Med. 2012;2(1):a006346.

95. Zhu F, Qian C. Berberine chloride can ameliorate the spatial memory impairment and increase the expression of interleukin-1beta and inducible nitric oxide synthase in the rat model of Alzheimer's disease. BMC Neurosci. 2006;7:78.

96. Cuello AC, Ferretti MT, Leon WC, et al. Early-stage inflammation and experimental therapy in transgenic models of the Alzheimer-like amyloid pathology. Neurodegener Dis. 2010;7(1-3):96-98.

97. Cai Z, Ratka A. Opioid system and Alzheimer's disease. Neuromolecular Med. 2012;14:91-111.

98. Cai Z, Xiao M, Chang L, Yan LJ. Role of insulin resistance in Alzheimer's disease. Metab Brain Dis. 2015;30(4):839-851.

99. Cai Z, Hussain MD, Yan LJ. Microglia, neuroinflammation, and betaamyloid protein in Alzheimer's disease. Int J Neurosci. 2014;124(5): 307-321.

100. Cai Z, Zhao Y, Zhao B. Roles of glycogen synthase kinase 3 in Alzheimer's disease. Curr Alzheimer Res. 2012;9(7):864-879.

101. Candore G, Bulati M, Caruso C, et al. Inflammation, cytokines, immune response, apolipoprotein E, cholesterol, and oxidative stress in Alzheimer disease: therapeutic implications. Rejuvenation Res. 2010;13(2-3):301-313.

102. Holmes C, Cunningham C, Zotova E, et al. Systemic inflammation and disease progression in Alzheimer disease. Neurology. 2009;73(10): 768-774.

103. Cai Z, Yan Y, Wang Y. Minocycline alleviates beta-amyloid protein and tau pathology via restraining neuroinflammation induced by diabetic metabolic disorder. Clin Interv Aging. 2013;8: 1089-1095.

104. Kulkarni SK, Dhir A. Berberine: a plant alkaloid with therapeutic potential for central nervous system disorders. Phytother Res. 2010;24(3): 317-324.

105. Lathe R, Sapronova A, Kotelevtsev Y. Atherosclerosis and Alzheimerdiseases with a common cause? Inflammation, oxysterols, vasculature. BMC Geriatr. 2014;14:36.

106. Kitazawa M, Trinh DN, LaFerla FM. Inflammation induces tau pathology in inclusion body myositis model via glycogen synthase kinase-3beta. Ann Neurol. 2008;64(1):15-24.

107. EikelenboomP, Rozemuller AJ, Hoozemans JJ, Veerhuis R, van GoolWA. Neuroinflammation and Alzheimer disease: clinical and therapeutic implications. Alzheimer Dis Assoc Disord. 2000;14(suppl 1): S54-S61.

108. Cai Z, Xiao M. Oligodendrocytes and Alzheimer's disease. Int $J$ Neurosci. 2016;126:97-104.

109. Kumar A, Ekavali, Mishra J, Chopra K, Dhull DK. Possible role of P-glycoprotein in the neuroprotective mechanism of berberine in intracerebroventricular streptozotocin-induced cognitive dysfunction. Psychopharmacology (Berl). 2016;233(1):137-152.

110. Patil S, Tawari S, Mundhada D, Nadeem S. Protective effect of berberine, an isoquinoline alkaloid ameliorates ethanol-induced oxidative stress and memory dysfunction in rats. Pharmacol Biochem Behav. 2015;136:13-20.

111. Ho FM, Liao YH, Yang AJ, et al. Anti-atherosclerotic action of GerGen-Chyn-Lian-Tang and AMPK-dependent lipid lowering effect in hepatocytes. J Ethnopharmacol. 2012;142(1):175-187.

112. Huang Z, Meng S, Wang L, Wang Y, Chen T, Wang C. Suppression of oxLDL-induced MMP-9 and EMMPRIN expression by berberine via inhibition of NF-kappaB activation in human THP-1 macrophages. Anat Rec (Hoboken). 2012;295:78-86.

113. Wu M, Wang J, Liu LT. Advance of studies on anti-atherosclerosis mechanism of berberine. Chin J Integr Med. 2010;16(2):188-192.

114. Wang Y, Jia X, Ghanam K, Beaurepaire C, Zidichouski J, Miller L. Berberine and plant stanols synergistically inhibit cholesterol absorption in hamsters. Atherosclerosis. 2010;209(1):111-117.

115. Sarna LK, Wu N, Hwang SY, Siow YL, O K. Berberine inhibits NADPH oxidase mediated superoxide anion production in macrophages. Can J Physiol Pharmacol. 2010;88(3):369-378. 
116. Ma YG, Zhang YB, Bai YG, et al. Berberine alleviates the cerebrovascular contractility in streptozotocin-induced diabetic rats through modulation of intracellular $\mathrm{Ca}(2+)$ handling in smooth muscle cells. Cardiovasc Diabetol. 2016;15:63.

117. Wang Q, Zhang M, Liang B, Shirwany N, Zhu Y, Zou MH. Activation of AMP-activated protein kinase is required for berberine-induced reduction of atherosclerosis in mice: the role of uncoupling protein 2. PLoS One. 2011;6(9):e25436.

118. Gong LL, Fang LH, Wang SB, et al. Coptisine exert cardioprotective effect through anti-oxidative and inhibition of RhoA/Rho kinase pathway on isoproterenol-induced myocardial infarction in rats. Atherosclerosis. 2012;222(1):50-58.

119. Huang Z, Cai X, Li S, et al. Berberineattenuated monocyte adhesion to endothelial cells induced by oxidized lowdensity lipoprotein via inhibition of adhesion molecule expression. Mol Med Rep. 2013;7: 461-465.

120. Zimetti F, Adorni MP, Ronda N, Gatti R, Bernini F, Favari E. The natural compound berberine positively affects macrophage functions involved in atherogenesis. Nutr Metab Cardiovasc Dis. 2015;25(2) 195-201.

121. Lee S, Lim HJ, Park HY, Lee KS, Park JH, Jang Y. Berberine inhibits rat vascular smooth muscle cell proliferation and migration in vitro and improves neointima formation after balloon injury in vivo. Berberine improves neointima formation in a rat model. Atherosclerosis 2006;186(1):29-37.

122. Cho BJ, Im EK, Kwon JH, et al. Berberine inhibits the production of lysophosphatidylcholine-induced reactive oxygen species and the ERK1/2 pathway in vascular smooth muscle cells. Mol Cells. 2005; 20(3):429-434

123. Chi L, Peng L, Pan N, Hu X, Zhang Y. The anti-atherogenic effects of berberine on foam cell formation are mediated through the upregulation of sirtuin 1. Int J Mol Med. 2014;34(4):1087-1093.

124. Fan X, Wang J, Hou J, et al. Berberine alleviates ox-LDL induced inflammatory factors by up-regulation of autophagy via AMPK/mTOR signaling pathway. J Transl Med. 2015;13:92.

125. Singh DP, Chopra K. Verapamil augments the neuroprotectant action of berberine in rat model of transient global cerebral ischemia. Eur $J$ Pharmacol. 2013;720(1-3):98-106.

126. Zhang X, Wang C, Li Y, et al. Neuroprotection of early and short-time applying berberine in the acute phase of cerebral ischemia: up-regulated pAkt, pGSK and pCREB, down-regulated NF-kappaB expression, ameliorated BBB permeability. Brain Res. 2012;1459:61-70.

127. Hu J, Chai Y, Wang Y, et al. PI3K p55 gamma promoter activity enhancement is involved in the anti-apoptotic effect of berberine against cerebral ischemia-reperfusion. Eur J Pharmacol. 2012;674: 132-142.

128. McCarty MF, O’Keefe JH, DiNicolantonio JJ. Red yeast rice plus berberine: practical strategy for promoting vascular and metabolic health. Altern Ther Health Med. 2015;21(suppl 2):40-45.

129. Chen W, Wei S, Yu Y, et al. Pretreatment of rats with increased bioavailable berberine attenuates cerebral ischemia-reperfusion injury via down regulation of adenosine-5'monophosphate kinase activity. Eur J Pharmacol. 2016;779:80-90.

130. Nadjafi S, Ebrahimi SA, Rahbar-Roshandel N. Protective effects of berberine on oxygen-glucose deprivation/reperfusion on oligodendrocyte cell line (OLN-93). Int J Prev Med. 2014;5(9):1153-1160.

131. Chai YS, Yuan ZY, Lei F, et al. Inhibition of retinoblastoma mRNA degradation through Poly (A) involved in the neuroprotective effect of berberine against cerebral ischemia. PLoS One. 2014;9(6):e90850.

132. Shen JD, Ma LG, Hu CY, et al. Berberine up-regulates the BDNF expression in hippocampus and attenuates corticosterone-induced depressive-like behavior in mice. Neurosci Lett. 2016;614:77-82.

133. Li K, Yao W, Zheng X, Liao K. Berberine promotes the development of atherosclerosis and foam cell formation by inducing scavenger receptor A expression in macrophage. Cell Res. 2009;19(8):1006-1017.

134. Zhang Q, Qian Z, Pan L, Li H, Zhu H. Hypoxia-inducible factor 1 mediates the anti-apoptosis of berberine in neurons during hypoxia/ ischemia. Acta Physiol Hung. 2012;99(3):311-323.
135. Kim YM, Ha YM, Jin YC, et al. Palmatine from coptidis rhizoma reduces ischemia-reperfusion-mediated acute myocardial injury in the rat. Food Chem Toxicol. 2009;47(8):2097-2102.

136. Halicka HD, Zhao H, Li J, et al. Potential anti-aging agents suppress the level of constitutive mTOR- and DNA damage-signaling. Aging (Albany NY). 2012;4(12):952-965.

137. Zhao H, Halicka HD, Li J, Darzynkiewicz Z. Berberine suppresses gero-conversion from cell cycle arrest to senescence. Aging (Albany NY). 2013;5(8):623-636

138. Xie J, Xu Y, Huang X, et al. Berberine-induced apoptosis in human breast cancer cells is mediated by reactive oxygen species generation and mitochondrial-related apoptotic pathway. Tumour Biol. 2015;36(2):1279-1288.

139. Meeran SM, Katiyar S, Katiyar SK. Berberine-induced apoptosis in human prostate cancer cells is initiated by reactive oxygen species generation. Toxicol Appl Pharmacol. 2008;229(1):33-43.

140. Eom KS, Kim HJ, So HS, Park R, Kim TY. Berberine-induced apoptosis in human glioblastoma T98G cells is mediated by endoplasmic reticulum stress accompanying reactive oxygen species and mitochondrial dysfunction. Biol Pharm Bull. 2010;33(10) $1644-1649$.

141. Qi MY, Feng Y, Dai DZ, Li N, Cheng YS, Dai Y. CPU86017, a berberine derivative, attenuates cardiac failure through normalizing calcium leakage and downregulated phospholamban and exerting antioxidant activity. Acta Pharmacol Sin. 2010;31(2):165-174.

142. Gao F, Gao Y, Liu YF, Wang L, Li YJ. Berberine exerts an anticonvulsant effect and ameliorates memory impairment and oxidative stress in a pilocarpine-induced epilepsy model in the rat. Neuropsychiatr Dis Treat. 2014;10:2139-2145.

143. Liu W, Liu P, Tao S, et al. Berberine inhibits aldose reductase and oxidative stress in rat mesangial cells cultured under high glucose. Arch Biochem Biophys. 2008;475(2):128-134.

144. Liu WH, Hei ZQ, Nie H, et al. Berberine ameliorates renal injury in streptozotocin-induced diabetic rats by suppression of both oxidative stress and aldose reductase. Chin Med J (Engl). 2008;121(8): 706-712.

145. Bhutada P, Mundhada Y, Bansod K, et al. Protection of cholinergic and antioxidant system contributes to the effect of berberine ameliorating memory dysfunction in rat model of streptozotocin-induced diabetes. Behav Brain Res. 2011;220(1):30-41.

146. Wang Y, Campbell T, Perry B, Beaurepaire C, Qin L. Hypoglycemic and insulin-sensitizing effects of berberine in high-fat diet- and streptozotocin-induced diabetic rats. Metabolism. 2011;60(2): 298-305

147. Lao-ong T, Chatuphonprasert W, Nemoto N, Jarukamjorn K. Alteration of hepatic glutathione peroxidase and superoxide dismutase expression in streptozotocin-induced diabetic mice by berberine. Pharm Biol. 2012;50(8):1007-1012.

148. Wang T, Zhao LJ, Li P, et al. Hepatoprotective effects and mechanisms of dehydrocavidine in rats with carbon tetrachloride-induced hepatic fibrosis. J Ethnopharmacol. 2011;138(1):76-84.

149. Sheng M, Zhou Y, Yu W, Weng Y, Xu R, Du H. Protective effect of Berberine pretreatment in hepatic ischemia/reperfusion injury of rat. Transplant Proc. 2015;47(2):275-282.

150. Zhu X, Guo X, Mao G, et al. Hepatoprotection of berberine against hydrogen peroxide-induced apoptosis by upregulation of Sirtuin 1. Phytother Res. 2013;27(3):417-421.

151. Dkhil MA. Role of berberine in ameliorating Schistosoma mansoniinduced hepatic injury in mice. Biol Res. 2014;47:8.

152. Germoush MO, Mahmoud AM. Berberine mitigates cyclophosphamide-induced hepatotoxicity by modulating antioxidant status and inflammatory cytokines. J Cancer Res Clin Oncol. 2014;140(7): 1103-1109.

153. Heidarian E, Rafieian-Kopaei M, Khoshdel A, Bakhshesh M. Metabolic effects of berberine on liver phosphatidate phosphohydrolase in rats fed on high lipogenic diet: an additional mechanism for the hypolipidemic effects of berberine. Asian Pac J Trop Biomed. 2014;4(suppl 1): S429-S435. 
154. Zhang $\mathrm{P}, \mathrm{Ma} \mathrm{D}$, Wang $\mathrm{Y}$, et al. Berberine protects liver from ethanolinduced oxidative stress and steatosis in mice. Food Chem Toxicol. 2014; $74: 225-232$.

155. Wang Y, Ding Y. Berberine protects vascular endothelial cells in hypertensive rats. Int J Clin Exp Med. 2015;8(9):14896-14905.

156. Liu L, Liu J, Huang Z, et al. Berberine improves endothelial function by inhibiting endoplasmic reticulum stress in the carotid arteries of spontaneously hypertensive rats. Biochem Biophys Res Commun. 2015;458(4):796-801.

157. Visnagri A, Kandhare AD, Bodhankar SL. Renoprotective effect of berberine via intonation on apoptosis and mitochondrial-dependent pathway in renal ischemia reperfusion-induced mutilation. Ren Fail. 2015;37(3):482-493.

158. Domitrovic R, Cvijanovic O, Pernjak-Pugel E, Skoda M, Mikelic L, Crncevic-Orlic Z. Berberine exerts nephroprotective effect against cisplatin-induced kidney damage through inhibition of oxidative/ nitrosative stress, inflammation, autophagy and apoptosis. Food Chem Toxicol. 2013;62:397-406.

159. Wan X, Chen X, Liu L, et al. Berberine ameliorates chronic kidney injury caused by atherosclerotic renovascular disease through the suppression of NFkappaB signaling pathway in rats. PLoS One. 2013;8:e59794.

160. Zhang P, Qiang X, Zhang M, et al. Demethyleneberberine, a natural mitochondria-targeted antioxidant, inhibits mitochondrial dysfunction, oxidative stress, and steatosis in alcoholic liver disease mouse model. J Pharmacol Exp Ther. 2015;352(1):139-147.

161. Yan HM, Xia MF, Wang Y, et al. Efficacy of berberine in patients with non-alcoholic fatty liver disease. PLoS One. 2015;10(8):e0134172.

162. Li J, Pan Y, Kan M, et al. Hepatoprotective effects of berberine on liver fibrosis via activation of AMP-activated protein kinase. Life Sci. 2014;98(1):24-30.

163. Yin J, Zhang H, Ye J. Traditional chinese medicine in treatment of metabolic syndrome. Endocr Metab Immune Disord Drug Targets. 2008; 8(2):99-111.

164. Kosaraju J, Chinni S, Roy PD, Kannan E, Antony AS, Kumar MN. Neuroprotective effect of Tinospora cordifolia ethanol extract on 6-hydroxy dopamine induced Parkinsonism. Indian J Pharmacol. 2014;46(2):176-180.

165. Song D, Song J, Wang C, Li Y, Dunaief JL. Berberine protects against light-induced photoreceptor degeneration in the mouse retina. Exp Eye Res. 2015;145:1-9.

166. Kim BY, Park HR, Jeong HG, Kim SW. Berberine reduce allergic inflammation in a house dust mite allergic rhinitis mouse model. Rhinology. 2015;53(4):353-358.

167. Li Z, Zheng J, Zhang N. Berberine improves airway inflammation and inhibits NF-kappaB signaling pathway in an ovalbumin-induced rat model of asthma. J Asthma. Epub 2016 May 13.

168. Chen J, Cao J, Fang L, et al. Berberine derivatives reduce atherosclerotic plaque size and vulnerability in apoE(-/-) mice. J Transl Med. 2014;12:326.
169. Li W, Hua B, Saud SM, et al. Berberine regulates AMP-activated protein kinase signaling pathways and inhibits colon tumorigenesis in mice. Mol Carcinog. 2015;54(10):1096-1109.

170. Sun SF, Zhao TT, Zhang HJ, et al. Renoprotective effect of berberine on type 2 diabetic nephropathy in rats. Clin Exp Pharmacol Physiol. 2015;42(6):662-670.

171. Ni WJ, Ding HH, Tang LQ. Berberine as a promising anti-diabetic nephropathy drug: an analysis of its effects and mechanisms. Eur $J$ Pharmacol. 2015;760:103-112.

172. Zhang Z, Li B, Meng X, et al. Berberine prevents progression from hepatic steatosis to steatohepatitis and fibrosis by reducing endoplasmic reticulum stress. Sci Rep. 2016;6:20848.

173. Gong Z, Chen Y, Zhang R, et al. Pharmacokinetic comparison of berberine in rat plasma after oral administration of berberine hydrochloride in normal and post inflammation irritable bowel syndrome rats. Int J Mol Sci. 2014;15(1):456-467.

174. Li XX, Li CB, Xiao J, et al. Berberine attenuates vascular remodeling and inflammation in a rat model of metabolic syndrome. Biol Pharm Bull. 2015;38(6):862-868.

175. Xu D, Wan C, Wang T, et al. Berberine attenuates cigarette smokeinduced airway inflammation and mucus hypersecretion in mice. Int J Clin Exp Med. 2015;8(6):8641-8647.

176. Yu L, Li Q, Yu B, et al. Berberine attenuates myocardial ischemia/ reperfusion injury by reducing oxidative stress and inflammation response: role of silent information regulator 1. Oxid Med Cell Longev. 2016;2016:1689602.

177. Qin-Wei Z, Yong-Guang LI. Berberine attenuates myocardial ischemia reperfusion injury by suppressing the activation of PI3K/AKT signaling. Exp Ther Med. 2016;11(3):978-984.

178. Zou ZY, Hu YR, Ma H, et al. Coptisine attenuates obesity-related inflammation through LPS/TLR-4-mediated signaling pathway in Syrian golden hamsters. Fitoterapia. 2015;105:139-146.

179. Liu SC, Lee HP, Hung CY, Tsai CH, Li TM, Tang CH. Berberine attenuates CCN2-induced IL-1beta expression and prevents cartilage degradation in a rat model of osteoarthritis. Toxicol Appl Pharmacol. 2015;289:20-29.

180. Kwon OJ, Kim MY, Shin SH, et al. Antioxidant and anti-inflammatory effects of rhei rhizoma and coptidis rhizoma mixture on reflux esophagitis in rats. Evid Based Complement Alternat Med. 2016;2016: 2052180.

181. Li J, Liu Z, Guo M, et al. Metabolomics profiling to investigate the pharmacologic mechanisms of berberine for the treatment of high-fat diet-induced nonalcoholic steatohepatitis. Evid Based Complement Alternat Med. 2015;2015:897914.

182. Chen CC, Hung TH, Lee CY, et al. Berberine protects against neuronal damage via suppression of glia-mediated inflammation in traumatic brain injury. PLoS One. 2014;9(12):e115694.

183. Chen G, Yang Y, Liu M, et al. Banxia xiexin decoction protects against dextran sulfate sodium-induced chronic ulcerative colitis in mice. J Ethnopharmacol. 2015;166:149-156.
Neuropsychiatric Disease and Treatment

\section{Publish your work in this journal}

Neuropsychiatric Disease and Treatment is an international, peerreviewed journal of clinical therapeutics and pharmacology focusing on concise rapid reporting of clinical or pre-clinical studies on a range of neuropsychiatric and neurological disorders. This journal is indexed on PubMed Central, the 'PsycINFO' database and CAS,

\section{Dovepress}

and is the official journal of The International Neuropsychiatric Association (INA). The manuscript management system is completely online and includes a very quick and fair peer-review system, which is all easy to use. Visit http://www.dovepress.com/testimonials.php to read real quotes from published authors. 